\title{
Correction
}

\section{Correction: Izquierdo et al. Resveratrol Supplementation Attenuates Cognitive and Molecular Alterations under Maternal High-Fat Diet Intake: Epigenetic Inheritance over Generations. Int. J. Mol. Sci. 2021, 22, 1453}

\author{
Vanesa Izquierdo $^{1}$, Verónica Palomera-Ávalos ${ }^{2}$, Mercè Pallàs ${ }^{1}$ (D) and Christian Griñán-Ferré ${ }^{1, *(D)}$ \\ 1 Department of Pharmacology and Therapeutic Chemistry, Institut de Neurociències-Universitat de Barcelona, \\ Avda. Joan XXIII, 27., 08028 Barcelona, Spain; vanessa_izquierdo@hotmail.com (V.I.); pallas@ub.edu (M.P.) \\ 2 Department of Cellular and Molecular Biology, University Center of Biological and Agricultural Sciences, \\ University of Guadalajara, km 15.5 Guadalajara-Nogales Highway, Zapopan 45110, Jalisco, Mexico; \\ vpalomera@hotmail.com \\ * Correspondence: christian.grinan@ub.edu; Tel.: +34-93-402-4526
}

check for updates

Citation: Izquierdo, V.;

Palomera-Ávalos, V.; Pallàs, M.;

Griñán-Ferré, C. Correction:

Izquierdo et al. Resveratrol

Supplementation Attenuates

Cognitive and Molecular Alterations under Maternal High-Fat Diet Intake: Epigenetic Inheritance over

Generations. Int. J. Mol. Sci. 2021, 22, 1453. Int. J. Mol. Sci. 2021, 22, 9155.

https://doi.org/10.3390/ijms22179155

Received: 12 July 2021

Accepted: 28 July 2021

Published: 25 August 2021

Publisher's Note: MDPI stays neutral with regard to jurisdictional claims in published maps and institutional affiliations.

Copyright: (c) 2021 by the authors. Licensee MDPI, Basel, Switzerland. This article is an open access article distributed under the terms and conditions of the Creative Commons Attribution (CC BY) license (https:// creativecommons.org/licenses/by/ $4.0 /)$.
The author wishes to make the following correction to this paper [1]:

In the original article, there was a mistake in Figure 5F. All WBs experiments were performed with 14 samples in total, where the 2 bands that are not shown correspond to the control group without dietary intervention, so the article shows the 12 bands that correspond to the HFD, HFD + RSV, HFD + RSV F1 and HFD + RSV F2. The corrected Figure 5F appears below.
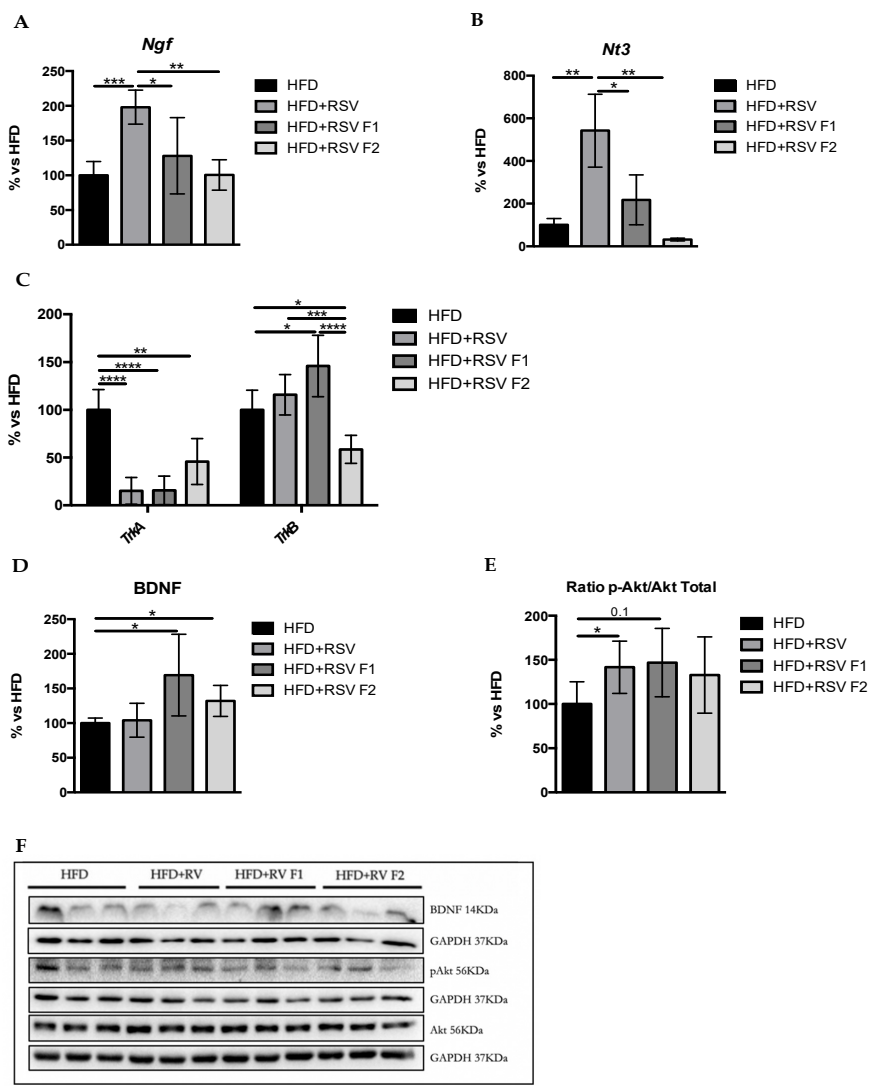

Figure 5. Synaptic plasticity markers in the hippocampus of SAMP8 mice at 6 months of age. Results of gene expression of $N g f(\mathbf{A}), N t 3$ (B), and their receptors, TrkA and TrkB (C). Quantifications (D,E) 
and representative results by $\mathrm{WB}$ of BDNF and p-Akt $(\mathbf{F})$. Gene expression levels were measured by real-time PCR from hippocampal tissue. Data from each group were compared with the HFD group (set at 100\%). The means and standard error of the mean (SEM) in bar graphs are adjusted to $100 \%$ for each gene of the HFD group; $n=16-24$ (HFD $n=4-6$, HFD + RSV $n=4-6$, HFD + RSV F1 $n=4-6$, HFD + RSV F2 $n=4-6$; for each group, females: $n=3-4$, males: $n=3-4)$. Statistics: ${ }^{*} p<0.05$; ** $p<0.01 ;{ }^{* * *} p<0.001 ; * * * * 0.0001$.

The authors apologize for any inconvenience caused and state that the scientific conclusions are unaffected. The original article has been updated.

Conflicts of Interest: The authors declare no conflict of interest.

\section{Reference}

1. Izquierdo, V.; Palomera-ávalos, V.; Pallàs, M.; Griñán-Ferré, C. Resveratrol supplementation attenuates cognitive and molecular alterations under maternal high-fat diet intake: Epigenetic inheritance over generations. Int. J. Mol. Sci. 2021, 22, 1453. [CrossRef] [PubMed] 